\title{
Relationship between alexithymia and coping strategies in patients with somatoform disorder
}

This article was published in the following Dove Press journal:

Neuropsychiatric Disease and Treatment

27 December 2013

Number of times this article has been viewed

\section{Toshiyuki Tominaga ${ }^{1,4}$ Hyungin $\mathrm{Choi}^{2}$ Yasuhide Nagoshi ${ }^{3}$ \\ Yoshihisa Wada ${ }^{4}$ \\ Kenji Fukui ${ }^{4}$}

'Health Management Doctor's Office (Mental Health), Salary, Personnel Health, and Welfare Division, Kyoto Prefecture, Japan; ${ }^{2}$ Department of Psychiatry, Iwakura Hospital, Kyoto, Japan; ${ }^{3}$ Department of Psychiatry (Psychosomatic Medicine), Kyoto First Red Cross Hospital, Kyoto, Japan; ${ }^{4}$ Department of Psychiatry, Graduate School of Medical Science, Kyoto Prefectural University of Medicine, Kyoto, Japan
Correspondence: Toshiyuki Tominaga Health Management Doctor's Office (Mental Health), Salary, Personnel Health, and Welfare Division, Yabunouti-cho, Nishiiru, Shinmachi, Simodatiuri-dori, Kamigyo-ku, Kyoto 602-8570, Japan

Tel +8 I 75 45 I 8I II

$\mathrm{Fax}+8 \mid 7545 । 8112$

Email totomi@koto.kpu-m.ac.jp
Purpose: A multidimensional intervention integrating alexithymia, negative affect, and type of coping strategy is needed for the effective treatment of somatoform disorder; however, few studies have applied this approach to the three different dimensions of alexithymia in patients with somatoform disorder. The purpose of this study was to determine the relationship between type of coping strategy and three different dimensions of alexithymia expressed in patients.

Patients and methods: A total of 196 patients with somatoform disorder completed the 20-item Toronto Alexithymia Scale, the Zung Self-Rating Depression Scale, the Spielberger State-Trait Anxiety Inventory, the Somatosensory Amplification Scale, and the Lazarus Stress Coping Inventory. The relationships between alexithymia (Toronto Alexithymia Scale - 20 score and subscales), demographic variables, and psychological inventory scores were analyzed using Pearson's correlation coefficients and stepwise multiple regression analysis.

Results: The mean Toronto Alexithymia Scale - 20 total score $(56.1 \pm 10.57)$ was positively correlated with the number of physical symptoms as well as with psychopathology scores (Self-Rating Depression Scale, State-Trait Anxiety Inventory trait, state, and Somatosensory Amplification Scale), but negatively correlated with planful problem solving, confrontive coping, seeking social support, and positive reappraisal coping scores. With respect to coping strategy, multiple regression analyses revealed that "difficulty in identifying feelings" was positively associated with an escape-avoidance strategy, "difficulty in describing feelings" was negatively associated with a seeking social support strategy, and "externally oriented thinking" was negatively associated with a confrontive coping strategy.

Conclusion: Alexithymia was strongly associated with the number of somatic symptoms and negative affect. Patients with high "difficulty in describing feelings" tend to rely less on seeking social support, and patients with high "externally oriented thinking" tend to rely less on confrontive coping strategies. The coping skills intervention implemented should differ across individuals and should be based on the alexithymia dimension of each patient.

Keywords: somatoform disorder, alexithymia, stress, coping strategies

\section{Introduction}

Somatoform disorder, characterized by recurrent and unexplainable physical symptoms, is observed in $16 \%-30 \%$ of primary psychiatric care patients, ${ }^{1-3}$ and is a frequent psychiatric diagnosis in specialty practice. ${ }^{4,5}$ Despite the high prevalence of somatoform disorder in epidemiological studies, no single definition is widely accepted. A central somatoform disorder category is somatization disorder, a condition defined by recurrent and frequently changing physical symptoms over the course of several years without any known medical condition. ${ }^{6}$ Somatoform disorder is strongly linked to pathological personality traits as well as to anxiety and depression. ${ }^{7,8}$ Personality pathology, 
in particular alexithymia, may be a predisposing factor in the development of somatoform disorder. Alexithymia, introduced by Sifneos, ${ }^{9}$ refers to a specific disturbance in psychic functioning that is characterized by difficulty in verbalizing emotional experiences and elaboration of fantasies. It is now generally referred to as a deficit in the cognitive processing of emotional information and has been reported in many psychiatric diseases involving disrupted emotional regulation, including panic disorder, ${ }^{10,11}$ substance abuse, ${ }^{12,13}$ fibromyalgia, ${ }^{14}$ and psychosomatic diseases with medically unexplained physical symptoms. ${ }^{15}$ Alexithymia has also been associated with maladaptive coping and illness-related behaviors, such as the over-reporting of physical symptoms and excessive use of health care services. ${ }^{15}$ Among somatic complaints, migraines are considered common during childhood. ${ }^{16}$ Children with headaches, and in particular those with migraines, are more likely to have other somatic symptoms, including abdominal pain, anxiety, and depression. ${ }^{17,18}$ Studies on cognitive functioning in children affected by headaches have received attention in recent years, ${ }^{19}$ and cognitive dysfunction of children with headache may be associated with alexithymia, and may lead to anxiety and depression. ${ }^{15}$

Although alexithymia is associated with poor outcomes in both traditional psychodynamic therapy and supportive therapy, ${ }^{20}$ recent studies have demonstrated a significant decrease in the level of alexithymia observed when modified psychotherapeutic techniques are used. ${ }^{21,22}$ Further, it has been suggested that alexithymia is a state-dependent phenomenon. $^{23}$

Coping strategies are constantly changing cognitive, behavioral, and emotional efforts engaged in by the individual in order to manage specific external and internal demands that are taxing or exceed the individual's resources. ${ }^{24,25}$ Coping skills can influence both illness-related behaviors and the outcome of disorders with psychological or physical symptoms, such as somatoform disorder, ${ }^{26}$ panic disorder, ${ }^{27}$ and chronic fatigue syndrome. ${ }^{28}$ Folkman and Lazarus developed the Ways of Coping Questionnaire, which consists of eight empirically derived scales. The eight scales can be classified as problem focused (ie, planful problem solving and confrontive coping strategies), emotion focused (ie, distancing, self-control, accepting responsibility, and escape-avoidance strategies), or both (ie, seeking social support and positive reappraisal strategies). ${ }^{29,30}$

To understand and effectively treat diseases with an alexithymia component, a multidimensional approach that targets not only negative affect but also the type of maladaptive coping strategy used is needed. To the authors' knowledge, however, few studies have investigated whether there is an association between alexithymia and type of coping strategy used in patients with somatoform disorder. The purpose of this study was to investigate the relationship between the level of alexithymia, psychosocial factors, and coping strategies. A deeper understanding of the relationship between alexithymia and coping strategies in somatoform disorder could lead to improved therapies.

\section{Methods \\ Subjects}

The subjects were a cross-section of 196 patients treated at the Department of Psychosomatics at Kyoto Prefectural University of Medicine (Kyoto, Japan). Screening and interviews took place between December 2005 and December 2012. Patients suspected of somatoform disorders at the Department of General Medicine at Kyoto Prefectural University of Medicine had been examined for organic disease through physical examinations and laboratory tests by physicians. Then patients were introduced to the Department of Psychosomatics. Diagnostic interviews were conducted by a certified psychiatrist of the Japanese Society of Psychiatry and Neurology, and patients were diagnosed according to the International Statistical Classification of Diseases, Tenth Revision (ICD-10 Diagnostic criteria for research) ${ }^{6}$ at the Department of Psychosomatics. Exclusion criteria included neurological disorders, organic disorders, mental retardation, and insufficient knowledge of the Japanese language. Patients responding to less than $70 \%$ of the test scale items were omitted from the analysis. This study was approved by the Ethical Review Committee of Kyoto Prefectural University of Medicine.

\section{Instruments}

Patients completed a questionnaire that collected information on demographic variables (eg, sex, age, education level, marital status) and a clinical profile (eg, duration of the illness, symptoms). There were four classifications of formal education: less than 9 years, 9-12 years, 12-15 years, and more than 15 years. Marital status was divided into five categories: single, married, divorced, separated, and widowed. Patients were also asked the number of previous visits to clinical departments (eg, internal medicine, family medicine, primary care, emergency room) and previous consultations with specialists. The overall number of somatic symptoms reported by individual patients ranged from zero to twelve according to the Screener for Somatoform Disorders. ${ }^{31}$ 
Symptoms included headache, racing heart, discomfort in the stomach or abdomen, back pain, dizziness, heaviness or lightness in the head, difficulty swallowing, muscle pains and aches, fatigue, heaviness or lightness in the arms or legs, numbness or tingling sensations, and crawling or creeping sensations.

Patients completed the Zung Self-Rating Depression Scale (SDS), ${ }^{32}$ the Spielberger State-Trait Anxiety Inventory (STAI), ${ }^{33}$ and the Somatosensory Amplification Scale (SSAS). ${ }^{34}$ The SDS is a 20 -item scale assessing depressive symptoms in which higher scores indicate more severe depression. The STAI measures state (I) and trait (II) anxiety with 40 self-report questions. The SSAS is a ten-item questionnaire assessing self-reported sensitivity to normal physiological states and minor bodily sensations that are not generally regarded as symptomatic of serious disease. ${ }^{35}$ The SSAS has been implicated in hypochondriasis and somatoform disorder. ${ }^{34,36}$

\section{Assessment of alexithymia}

Alexithymia was measured using the 20 -item version of the Toronto Alexithymia Scale (TAS-20). The TAS-20 consists of 20 items rated on a five-point Likert scale ranging from one ("strongly disagree") to five ("strongly agree"). The TAS-20 tests three dimensions of alexithymia: difficulty in identifying feelings (DIF), difficulty in describing feelings (DDF), and externally oriented thinking (EOT). The DIF and DDF dimensions refer to emotional awareness and reflect what may be considered "affect-related" factors that rely on the person's beliefs about emotional functioning, whereas EOT refers to a specific tendency to focus on superficial themes rather than psychological experiences and to avoid affective thinking. ${ }^{37}$ Therefore, EOT can be considered a "cognitive" factor. The factor structure of TAS-20 has been validated by confirmatory factor analysis. ${ }^{38}$

\section{Measures of stress coping strategies}

Coping strategies were assessed using the Lazarus Stress Coping Inventory, and the Japanese version of the Ways of Coping Questionnaire (SCI). ${ }^{39,40}$ The SCI scale consists of 64 items that probe the frequency of specific coping strategies when faced with stressful situations. Each component of the inventory is scored on a three-point Likert scale ranging from zero ("I don't do this at all") to two ("I usually do this a lot"). The SCI is divided into eight factors: 1) planful problem solving (deliberate analytic efforts to alter or remedy the situation); 2) confrontive coping (efforts to identify the cause of the problem and eliminate the source); 3) seeking social support (efforts to seek informational, tangible, and emotional support from others); 4) accepting responsibility (acknowledging one's role in the problem with rectification); 5) self-control (efforts to control one's feelings and actions); 6) escape-avoidance (wishful thinking to escape or avoid the problem); 7) distancing (efforts to detach oneself and to minimize the significance of the situation); and 8) positive reappraisal (efforts to create a positive meaning and personal growth).

\section{Statistical analysis}

Demographic variables and all psychometric scales are presented as mean \pm standard deviation or as percentages within specific ranges. To examine the relationship between alexithymia and other psychological factors, Pearson's correlation coefficients were used. In addition, stepwise multiple regression analyses were performed with TAS20 subscale scores as the dependent variable. Candidate factors influencing alexithymia were entered as independent variables in each model. For all tests, $P<0.05$ was considered statistically significant. All statistical tests were calculated using SPSS ${ }^{\circledR}$ version 19.0 for Windows (IBM Corporation, Armonk, NY, USA).

\section{Results \\ Patient characteristics}

Clinical and demographic characteristics of the 196 somatoform disorder patients enrolled are shown in Table 1. Of the total cohort, 131 were women $(66.8 \%)$ and 93 were single $(47.4 \%)$. The mean age of the sample was $41.3 \pm 15.4$ years, and the education level was $14.2 \pm 1.89$ years.

\section{Associations between alexithymia and psychological factors}

Table 2 presents the mean psychological test scores. The mean number of somatic symptoms was $4.9 \pm 1.9$. On the TAS-20, the mean total score was $56.2 \pm 10.6$. On the SSAS, the mean score was $30.8 \pm 5.9$. Correlations between the TAS-20 scores and the various demographic variables and psychological symptoms are shown in Table 3. The TAS-20 total score was significantly correlated with age and with the total scores from the Screener for Somatoform Disorders, SDS, STAI-state (I) and -trait (II), and SSAS. The subscale for the DIF and DDF were negatively correlated with age and positively correlated with the Screener for Somatoform Disorders, SDS, STAI-state (I) and -trait (II), and SSAS scores. 
Table I Demographics in patients with somatoform disorder $(\mathrm{N}=196)$

\begin{tabular}{|c|c|c|}
\hline Patient characteristics & $\mathbf{N}$ & $\%$ \\
\hline \multicolumn{3}{|l|}{ Sex } \\
\hline Female & 131 & 66.8 \\
\hline Male & 65 & 33.2 \\
\hline Mean (SD) age, years & $4 I .27(15.4)$ & \\
\hline \multicolumn{3}{|l|}{ Educational level } \\
\hline Junior high school, $<10$ years & 3 & 1.5 \\
\hline Senior high school, $<13$ years & 56 & 28.6 \\
\hline College, $<15$ years & 52 & 26.5 \\
\hline University, $\geq 15$ years & 85 & 38.8 \\
\hline \multicolumn{3}{|l|}{ Marital status } \\
\hline Single & 93 & 47.4 \\
\hline Married & 71 & 36.2 \\
\hline Separated & 4 & 2.0 \\
\hline Divorced & 25 & 12.8 \\
\hline Widowed & 3 & 1.5 \\
\hline \multicolumn{3}{|l|}{ Employment } \\
\hline In school & 8 & 4.1 \\
\hline Housewife & 47 & 24.0 \\
\hline Retired & 5 & 2.6 \\
\hline Worker (employed) & 136 & 69.4 \\
\hline \multicolumn{3}{|l|}{ Living situation } \\
\hline Living with partner or parents & 144 & 73.5 \\
\hline Living alone & 50 & 25.5 \\
\hline \multicolumn{3}{|l|}{ ICDIO } \\
\hline 45.0 Somatization disorder & 3 & 1.5 \\
\hline 45.I Undifferentiated somatoform disorder & 47 & 24.0 \\
\hline 45.3 Somatoform autonomic dysfunction & 46 & 23.5 \\
\hline 45.4 Persistent somatoform pain disorder & 20 & 10.2 \\
\hline 45.8 Other somatoform disorders & 43 & 21.9 \\
\hline 45.9 Somatoform disorder, unspecified & 37 & 18.9 \\
\hline
\end{tabular}

Abbreviations: ICDI0, International Classification of Diseases, Tenth Revision; SD, standard deviation.

\section{Relationship between alexithymia and coping strategies}

The TAS-20 total score, DDF, and EOT were each significantly and negatively correlated with the SCI subscores for planful problem coping (TAS-20: $r=-0.25, P<0.001$; DDF: $r=-0.23, P<0.01$; EOT: $r=-0.26, P<0.001)$, confrontive coping (TAS-20: $r=-0.18, P<0.05$; DDF: $r=-0.18$, $P<0.05$; EOT: $r=-0.34, P<0.001)$, seeking social support (TAS-20: $r=-0.25, P<0.001$; DDF: $r=-0.28, P<0.001$; EOT: $r=-0.25, P<0.001$ ), and positive reappraisal (TAS-20: $r=-0.29, P<0.001$; DDF; $\mathrm{r}=-0.25, P<0.001$; EOT; $r=-0.30$, $P<0.001)$.

A multiple regression model was used to assess possible independent predictors of the TAS-20 total score and the three subscale scores. The final model for the TAS-20 total score was significant (adjusted $R^{2}=0.43, P<0.001$ ), with STAI-trait (II), SSAS, and the SCI subscale "seeking social support," explaining $42.5 \%$ of the variance $(F=49.3$,
Table 2 Mean scores on the 20-item Toronto Alexithymia Scale, Screener for Somatoform Disorders, Somatosensory Amplification Scale, Zung Self-Rating Depression Scale, Spielberger State-Trait Anxiety Inventory, and Stress Coping Inventory

\begin{tabular}{lll}
\hline & Mean & SD \\
\hline Prior visits to clinical departments & 3.64 & 2.33 \\
Duration of somatic symptoms, months & 14.30 & 21.07 \\
Number of somatic symptoms (SSD) & 4.93 & 1.93 \\
SSAS & 30.78 & 5.92 \\
SDS & 51.28 & 9.27 \\
STAI-trait (II) & 57.73 & 11.06 \\
STAI-state (I) & 55.91 & 10.31 \\
TAS-20 & 56.21 & 10.57 \\
DIF & 20.76 & 6.12 \\
DDF & 15.95 & 4.33 \\
EOT & 19.55 & 3.94 \\
Stress Coping Scale & & \\
Planful problem solving & 6.57 & 3.77 \\
Confrontive coping & 6.06 & 3.33 \\
Seeking social support & 6.42 & 4.07 \\
Accepting responsibility & 7.35 & 4.10 \\
Self-control & 6.88 & 3.21 \\
Escape-avoidance & 5.91 & 2.83 \\
Distancing & 5.42 & 3.18 \\
Positive reappraisal & 6.44 & 3.97 \\
\hline Not Vists to prior clinica
\end{tabular}

Note: Visits to prior clinical departments included those to internal medicine, family medicine, the emergency room, and specialists.

Abbreviations: DDF, difficulty in describing feelings; DIF, difficulty in identifying feelings; EOT, externally oriented thinking; SDS, Zung Self-Rating Depression Scale; SSAS, Somatosensory Amplification Scale; SSD, Screener for Somatoform Disorders; STAl, Spielberger State-Trait Anxiety Inventory; TAS-20, 20-item Toronto Alexithymia Scale.

$P<0.001)$. Similarly, multiple linear regression analyses were performed for each TAS-20 subscale (DIF, DDF, and EOT) and the results are presented in Table 4. In the DIF model, STAI-trait (II), SSAS, and the SCI subscale "escape-avoidance" predicted the DIF $(F=37.2, P<0.001)$. In the DDF model, age, STAI-trait (II), and the SCI subscale "seeking social support" predicted the DDF $(F=42.4$, $P<0.001)$. In the EOT model, STAI-state (I) and the SCI subscale "confrontive coping" predicted the EOT $(F=17.3$, $P<0.001)$.

\section{Discussion}

\section{Demographics and psychological factors}

First, the results of the present study demonstrated a strong correlation between alexithymia, as measured by TAS-20, the number of physical symptoms, SSAS, and negative affect (including anxiety and depression). With regard to the subscales, the affective dimensions DIF and DDF were strongly associated with STAI and SDS scores and consistent with the results of several previous studies that included patients with medically unexplained symptoms ${ }^{41}$ and pain disorder. ${ }^{42}$ 
Table 3 Associations between the 20-item Toronto Alexithymia Scale, demographic variables, psychological variables, and the Stress Coping Scale

\begin{tabular}{|c|c|c|c|c|}
\hline & TAS-20 & DIF & DDF & EOT \\
\hline Age & $-0.27 * * *$ & $-0.24 * * *$ & $-0.4 I * * *$ & 0.09 \\
\hline Sex & 0.10 & $0.18 *$ & 0.09 & -0.12 \\
\hline $\begin{array}{l}\text { Duration of somatic } \\
\text { symptoms, months }\end{array}$ & 0.06 & 0.01 & 0.05 & 0.11 \\
\hline $\begin{array}{l}\text { Number of previous } \\
\text { clinic visits }\end{array}$ & -0.08 & 0.03 & -0.03 & -0.05 \\
\hline $\begin{array}{l}\text { Number of somatic } \\
\text { symptoms (SSD) }\end{array}$ & $-0.35^{* * *}$ & $0.31 * * *$ & $0.27^{* * *}$ & $0.15^{*}$ \\
\hline \multicolumn{5}{|l|}{ Psychological variables } \\
\hline SDS & $0.49 * * *$ & $0.45^{* * *}$ & $0.47^{* * *}$ & 0.11 \\
\hline STAI-state (I) & $0.61^{* * *}$ & $0.42^{* * *}$ & $0.27^{* * *}$ & $0.18^{*}$ \\
\hline STAI-trait (II) & $0.6 I^{* * *}$ & $0.54 * * *$ & $0.53^{* * *}$ & $0.20 * *$ \\
\hline SSAS & $0.43^{* * *}$ & $0.44^{* * *}$ & $0.37^{* * *}$ & 0.08 \\
\hline \multicolumn{5}{|l|}{ Stress Coping Scale } \\
\hline Planful problem solving & $-0.25 * * *$ & -0.10 & $-0.23 * *$ & $-0.26 * * *$ \\
\hline Confrontive coping & $-0.18^{*}$ & 0.03 & $-0.18^{*}$ & $-0.34 * * *$ \\
\hline Seeking social support & $-0.25 * * *$ & -0.07 & $-0.28 * * *$ & $-0.25 * * *$ \\
\hline Accepting responsibility & 0.07 & 0.13 & 0.07 & -0.08 \\
\hline Self-control & 0.00 & 0.12 & 0.00 & $-0.20 * *$ \\
\hline Escape-avoidance & 0.09 & $0.21 *$ & 0.02 & -0.09 \\
\hline Distancing & -0.01 & 0.10 & -0.05 & -0.12 \\
\hline Positive reappraisal & $-0.29 * * *$ & -0.13 & $-0.25 * * *$ & $-0.30 * * *$ \\
\hline
\end{tabular}

Note: $* P<0.05 ; * * P<0.01 ; * * * P<0.001$.

Abbreviations: DDF, difficulty in describing feelings; DIF, difficulty in identifying feelings; EOT, externally oriented thinking; SDS, Zung Self-Rating Depression Scale; SSAS, Somatosensory Amplification Scale; SSD, Screener for Somatoform Disorders; STAI, Spielberger State-Trait Anxiety Inventory; TAS-20, 20-item Toronto Alexithymia Scale.

Regarding the relationships between alexithymia and psychiatric disorders, Son et $\mathrm{al}^{43}$ has reported that patients with depressive disorder obtained higher scores for DIF and DDF than those with somatoform disorder. The present correlation analysis results revealed that the depression score was significantly correlated with both DIF and DDF, which suggests that depression plays a more important role even in somatoform disorder. However, the regression analyses indicated that anxiety score has a greater effect on both DIF and DDF than depression score. This result may reflect that not only depression but anxiety relates to DIF and DDF in somatoform disorder. Thus, further research is needed to clarify the relevance of alexithymia and negative affect (ie, depression and anxiety) in each psychiatric disorder (ie, somatoform disorder, depressive disorder, and anxiety disorder).

In addition, the present findings are consistent with evidence that alexithymia is associated with an increased likelihood of somatic complaints, symptom reporting, ${ }^{44,45}$ and functional dyspepsia. ${ }^{46}$ Kano and Fukudo ${ }^{47}$ suggested that individuals with alexithymia tend to over-report physical
Table 4 Results from the multiple regression analyses on the 20 -item Toronto Alexithymia Scale total score with the three subscales as dependent variables

\begin{tabular}{|c|c|c|c|c|c|}
\hline & \multicolumn{2}{|c|}{$\begin{array}{l}\text { Unstandardized } \\
\text { coefficients }\end{array}$} & \multirow{2}{*}{$\begin{array}{l}\text { Standardized } \\
\text { coefficients } \\
\beta\end{array}$} & \multirow[t]{2}{*}{$t$} & \multirow[t]{2}{*}{$P$} \\
\hline & $\beta$ & SE & & & \\
\hline \multicolumn{6}{|l|}{ TAS-20 } \\
\hline STAI-trait (II) & 0.47 & 0.06 & 0.49 & 8.14 & $* * *$ \\
\hline SSAS & 0.38 & 0.11 & 0.21 & 3.47 & $* * *$ \\
\hline $\begin{array}{l}\text { Seeking social } \\
\text { support }\end{array}$ & -0.47 & 0.14 & -0.18 & -3.34 & $* * *$ \\
\hline \multicolumn{6}{|l|}{ DIF } \\
\hline STAI-trait (II) & 0.24 & 0.04 & 0.43 & 6.74 & $* * *$ \\
\hline SSAS & 0.22 & 0.07 & 0.21 & 3.30 & $* *$ \\
\hline $\begin{array}{l}\text { Escape- } \\
\text { avoidance }\end{array}$ & 0.33 & 0.13 & 0.15 & 2.60 & $*$ \\
\hline \multicolumn{6}{|l|}{ DDF } \\
\hline Age & -0.08 & 0.02 & -0.27 & -4.63 & $* * *$ \\
\hline STAI-trait (II) & 0.17 & 0.02 & 0.44 & 7.50 & $* * *$ \\
\hline $\begin{array}{l}\text { Seeking social } \\
\text { support }\end{array}$ & -0.22 & 0.06 & -0.20 & -3.62 & $* * *$ \\
\hline \multicolumn{6}{|l|}{ EOT } \\
\hline STAI-state (I) & 0.07 & 0.03 & 0.19 & 2.82 & $* *$ \\
\hline $\begin{array}{l}\text { Confrontive } \\
\text { coping }\end{array}$ & -0.41 & 0.08 & -0.35 & -5.25 & $* * *$ \\
\hline
\end{tabular}

Notes: $* P<0.05 ; * * P<0.01 ; * * * P<0.00$; TAS-20: $R^{2}=0.434$, adjusted $R^{2}=0.425$, $F=49.34$; DIF: $R^{2}=0.366$, adjusted $R^{2}=0.356, F=37.15$; DDF: $R^{2}=0.63$, adjusted $R^{2}=0.40$, $F=42.4$; EOT: $R^{2}=0.152$, adjusted $R^{2}=0.143, F=17.32$.

Abbreviations: DDF, difficulty in describing feelings; DIF, difficulty in identifying feelings; EOT, externally oriented thinking; SE, standard error; STAI, Spielberger State-Trait Anxiety Inventory; TAS-20, 20-item Toronto Alexithymia Scale; SSAS, Somatosensory Amplification Scale.

symptoms and perceive any emotion-related sensation, even those with low intensity, as signs of illness. High DIF and DDF scores may contribute to the development of somatoform disorders through a focus on somatic sensations, amplification of the somatic sensations with emotional arousal, and misinterpretation of the somatic sensations associated with emotional arousal as signs of physical illness. Esposito et al have shown that children with headaches had a lower verbal intelligence quotient than healthy controls on a test of cognitive functioning. ${ }^{19}$ This may indicate that individuals with psychosomatic disease that includes headaches have difficulty describing feelings, as in alexithymia. In addition, cognitive dysfunction may lead to anxiety and depression, which further compounds the tendency for somatization and becomes more severe through a process of selfreinforcement.

The finding that age was negatively correlated with the TAS-20 total score, DIF subscale score, and DDF subscale score, but not with EOT, is consistent with a preceding report about alexithymia in psychiatric disorders. ${ }^{43}$ Japanese custom may have a strong influence on this relationship: Japanese 
people, especially the young, are poor at expressing their feelings in various situations and may tend to refrain from doing so in order to achieve social harmony. This tendency represents the general communication climate in this geographical region. ${ }^{48}$

\section{Coping strategies}

The focus of this study was the direct relationship between alexithymia and specific coping strategies. To the authors' knowledge, this is the first report to show a relationship between the three dimensions of alexithymia and coping strategies in somatoform disorder.

The finding that the DIF subscale was associated with the emotional escape-avoidance coping strategy is consistent with previous research in somatoform disorder. ${ }^{23}$ Waller and Scheidt showed that patients with somatoform disorder are characterized by a conflict-avoidance style of emotion regulation. ${ }^{49}$ Patients with a high DIF score are unable to discern emotions from somatic sensations. An increased reliance on avoidant coping strategies may be the result of confusion regarding the increase in uncomfortable and undifferentiated feelings that occur during stressful situations in these patients. For example, Esposito et al indicated that children affected by migraines showed a higher prevalence of harm avoidance with respect to a control group, which is consistent with Cloninger's model. ${ }^{16}$ Although Lazarus's theory is not identical to Cloninger's psychobiological model of temperament dimensions, harm avoidance (formulated as the inhibition of behavior by anxiety-provoking stimuli) is united with avoidance behavior in order to escape or prevent a stressful situation. Clinicians should empathize with patients' anguish and use an intervention focused on educating the patients about the emotional dimension. Such interventions assist patients in developing better emotional skills and include instruction on distinguishing a feeling from a somatic sensation, labeling the feeling, and feeling self-monitoring.

A strong association between DDF scores and social support coping strategies was also found. The DDF measures the inability to verbalize one's emotions to others. Fukunishi and Rahe found that individuals with alexithymia were more likely to indicate having lower social support. ${ }^{50}$ Patients with high DDF scores may experience difficulty with social interactions and lack interpersonal understanding, which may lead to lower social functioning; in turn, the patient may be less likely to seek social support and less likely to communicate their problems to others. Alexithymia has been associated with deficits in empathy, and those deficits result in patients having difficulty identifying the emotional facial expressions of others. ${ }^{51}$ Neuroimaging of patients with alexithymia has shown less activation in the limbic areas, prefrontal cortex, and area of right hemisphere associated with emotional awareness when patients are asked to view facial expressions. ${ }^{48,52}$ This neurobiological response to emotional facial stimuli is similar to that in somatoform disorder. ${ }^{53,54}$ Moreover, this misinterpretation of others' facial expressions combined with a low ability in verbal expression has a negative influence on individuals' social functioning and leads to a worsening of social relations. Therefore, interventions aimed at strengthening communication skills through assertion training, information gathering, and seeking the cooperation of others in conflict resolution may be well suited to patients with high DDF scores.

Finally, EOT score was strongly related to a deficient confrontive coping strategy. EOT is characterized by actionoriented thinking that focuses on the factual aspects of external reality rather than on the psychological experience. Individuals with high EOT scores are less likely to cope with the stress of intractable problems (ie, they are less likely to seek the elimination of the source with confidence). A confrontive coping strategy (a form of problem-focused coping) attempts to realistically identify the cause of the problem and to eliminate the source. The more infrequent use of this strategy may be partly due to difficulty in discerning the source of the stress and confidently working toward a solution. Thus, for patients with high EOT scores, useful intervention approaches may include techniques that promote the understanding that physical symptoms can be related to the stressful situation and techniques that aid in identifying the cause of the problem while enhancing the patient's confidence.

Although alexithymia was associated with poor outcomes in both traditional psychodynamic therapy and supportive therapy, recent studies have suggested that alexithymia is a transdiagnostic deficit. ${ }^{55}$ Furthermore, modified psychotherapeutic techniques (ie, psychodynamic group therapy focusing on the verbalization of individual emotional problems ${ }^{20}$ and short-term cognitive-behavioral group therapy ${ }^{56}$ ) result in a significant decrease in the level of alexithymia. Some researchers have suggested that cognitive-behavioral therapy is an effective treatment for somatoform disorders. ${ }^{57-59}$ Both individuals with somatoform disorders and those with alexithymia have difficulty verbally expressing emotions, understanding the mind-body connection, and have poor social coping skills. The results of the present study suggest that interventions focused on 
coping skills training may be appropriate for patients with alexithymia. Because the TAS-20 encompasses three dimensions, clinicians should refine coping skills interventions to the features of the relevant dimensions for individual patients.

\section{Limitations}

The present study had several limitations. First, because there was no control group, the authors were unable to determine whether the observed relationships between alexithymia and coping strategies are specific to somatoform disorder. Second, all the dependent measures were based on self-report. Individuals with alexithymia may find the selfevaluation asked of them in this study difficult due to their poor cognitive processing of emotion. Future studies should include observer scales, such as the Beth Israel Hospital Psychosomatic Questionnaire, that do not rely on self-report. Finally, the cross-sectional design does not allow the direct evaluation of causality. The present study showed that alexithymia was significantly correlated with the psychological factors of depression and anxiety, and with specific coping strategies. Also, negative affect exerted greater influence over personal coping skills. Together, this indicates that the three factors (ie, alexithymia, negative affect, and coping skills) are mutually related. Nonetheless, it was found that the association between alexithymia and coping strategies is independent of other psychological factors, such as depression and anxiety.

Knowledge of the alexithymia level may be useful at the onset of treatment because these patients may respond particularly well to therapies that promote adaptive coping styles. The relationship between individual coping strategies and psychological and physical problems is complex and multidimensional, and involves access to social communication and other contextual factors. Because of the aforementioned limitations of this study, prospective follow-up studies are necessary to reach a solid conclusion. Future studies are needed to determine whether a therapeutic program that focuses on increasing adaptive coping skills is more effective for somatoform disorder than the treatments that are currently employed.

\section{Conclusion}

Alexithymia is strongly associated with a number of somatic symptoms and negative affect in patients with somatoform disorder. Patients with high "difficulty in describing feelings" tend to rely less on seeking social support, and patients with high "externally oriented thinking" tend to rely less on confrontive coping strategies. The type of coping skill intervention should be selected according to the features individual patients with alexithymia express in somatoform disorder.

\section{Disclosure}

The authors report no conflicts of interest in this work.

\section{References}

1. Steinbrecher N, Hiller W. Course and prediction of somatoform disorder and medically unexplained symptoms in primary care. Gen Hosp Psychiatry. 2011;33(4):318-326.

2. Fink P, Sorensen L, Engberg M, Holm M, Munk-Jorgensen P. Somatization in primary care. Prevalence, health care utilization, and general practitioner recognition. Psychosomatics. 1999;40(4):330-338.

3. de Waal MW, Arnold IA, Eekhof JA, van Hemert AM. Somatoform disorders in general practice: prevalence, functional impairment and comorbidity with anxiety and depressive disorders. Br J Psychiatry. 2004; 184:470-476.

4. Barsky AJ, Orav EJ, Bates DW. Distinctive patterns of medical care utilization in patients who somatize. Med Care. 2006;44(9):803-811.

5. Reid S, Wessely S, Crayford T, Hotopf M. Medically unexplained symptoms in frequent attenders of secondary health care: retrospective cohort study. BMJ. 2001;322(7289):767.

6. World Health Organization. The ICD-10 Classification of Mental and Behavioral Disorders: Diagnostic Criteria for Research. Geneva: World Health Organization; 1993. Available from: http://www.who.int/ classifications/icd/en/GRNBOOK.pdf. Accessed November 15, 2013.

7. Fukunishi I, Kaji N, Hosaka T, Berger D, Rahe RH. Relationship of alexithymia and poor social support to ulcerative changes on gastrofiberscopy. Psychosomatics. 1997;38(1):20-26.

8. Rasmussen NH, Agerter DC, Baird MA, Yunghans CE, Cha SS Somatization and alexithymia in patients with high use of medical care and medically unexplained symptoms. Ment Health Fam Med. 2008;5(3):139-148.

9. Sifneos PE. The prevalence of "alexithymic" characteristics in psychosomatic patients. Psychother Psychosom. 1973;22(2):255-262.

10. Majohr KL, Leenen K, Grabe HJ, Jenewein J, Nunez DG, Rufer M. Alexithymia and its relationship to dissociation in patients with panic disorder: J Nerv Ment Dis. 2011;199(10):773-777.

11. Galderisi S, Mancuso F, Mucci A, Garranobe S, Zamboli R, Maj M. Alexithymia and cognitive dysfunctions in patients with panic disorder. Psychother Psychosom. 2008;77(3):182-188.

12. Coriale G, Bilotta E, Leone L, et al. Avoidance coping strategies, alexithymia and alcohol abuse: a mediation analysis. Addict Behav. 2012;37(11):1224-1229.

13. Stasiewicz PR, Bradizza CM, Gudleski GD, et al. The relationship of alexithymia to emotional dysregulation within an alcohol dependent treatment sample. Addict Behav. 2012;37(4):469-476.

14. Sayar K, Gulec H, Topbas M. Alexithymia and anger in patients with fibromyalgia. Clin Rheumatol. 2004;23(5):441-448.

15. Kooiman CG, Bolk JH, Brand R, Trijsburg RW, Rooijmans HG. Is alexithymia a risk factor for unexplained physical symptoms in general medical outpatients? Psychosom Med. 2000;62(6):768-778.

16. Esposito M, Marotta R, Gallai B, et al. Temperamental characteristics in childhood migraine without aura: a multicenter study. Neuropsychiatr Dis Treat. 2013;9:1187-1192.

17. Bellini B, Arruda M, Cescut A, et al. Headache and comorbidity in children and adolescents. $J$ Headache Pain. 2013;14(1):79.

18. Bruijn J, Locher H, Passchier J, Dijkstra N, Arts WF. Psychopathology in children and adolescents with migraine in clinical studies: a systematic review. Pediatrics. 2010;126(2):323-332.

19. Esposito M, Pascotto A, Gallai B, et al. Can headache impair intellectual abilities in children? An observational study. Neuropsychiatr Dis Treat. 2012;8:509-513. 
20. Sifneos PE. Problems of psychotherapy of patients with alexithymic characteristics and physical disease. Psychother Psychosom. 1975;26(2): 65-70.

21. Grabe HJ, Frommer J, Ankerhold A, et al. Alexithymia and outcome in psychotherapy. Psychother Psychosom. 2008;77(3):189-194.

22. Taylor GJ, Bagby RM. New trends in alexithymia research. Psychother Psychosom. 2004;73(2):68-77.

23. Honkalampi K, Hintikka J, Laukkanen E, Lehtonen J, Viinamaki H. Alexithymia and depression: a prospective study of patients with major depressive disorder. Psychosomatics. 2001;42(3):229-234.

24. Folkman S, Lazarus RS. If it changes it must be a process: study of emotion and coping during three stages of a college examination. J Pers Soc Psychol. 1985;48(1):150-170.

25. Folkman S, Lazarus RS, Dunkel-Schetter C, DeLongis A, Gruen RJ. Dynamics of a stressful encounter: cognitive appraisal, coping, and encounter outcomes. J Pers Soc Psychol. 1986;50(5):992-1003.

26. Rasmussen NH, Agerter DC, Bernard ME, Cha SS. Coping style in primary care adult patients with abridged somatoform disorders. Ment Health Fam Med. 2010;7(4):197-207.

27. Hino T, Takeuchi T, Yamanouchi N. A 1-year follow-up study of coping in patients with panic disorder. Compr Psychiatry. 2002;43(4): 279-284.

28. Afari N, Schmaling KB, Herrell R, Hartman S, Goldberg J, Buchwald DS. Coping strategies in twins with chronic fatigue and chronic fatigue syndrome. J Psychosom Res. 2000;48(6):547-554.

29. Matsumoto Y, Sato T, Ohnishi M, Kishimoto Y, Terada S, Kuroda S. Stress-coping strategies of patients with gender identity disorder. Psychiatry Clin Neurosci. 2009;63(6):715-720.

30. Penley JA, Tomaka J, Wiebe JS. The association of coping to physical and psychological health outcomes: a meta-analytic review. J Behav Med. 2002;25(6):551-603.

31. Isaac M, Janca A, Burke KC, et al. Medically unexplained somatic symptoms in different cultures. A preliminary report from Phase I of the World Health Organization International Study of Somatoform Disorders. Psychother Psychosom. 1995;64(2):88-93.

32. Zung WW. A self-rating depression scale. Arch Gen Psychiatry. 1965;12:63-70.

33. Spielberger CD, Gorsuch RL, Lushene RE. Manual for State-Trait Anxiety Inventory (STAI). Palo Alto, CA: Consulting Psychologists Press; 1970.

34. Barsky AJ, Goodson JD, Lane RS, Cleary PD. The amplification of somatic symptoms. Psychosom Med. 1988;50(5):510-519.

35. Barsky AJ, Bailey ED, Fama JM, Ahern DK. Predictors of remission in DSM hypochondriasis. Compr Psychiatry. 2000;41(3):179-183.

36. Nakao M, Barsky AJ. Clinical application of somatosensory amplification in psychosomatic medicine. Biopsychosoc Med. 2007;1:17.

37. Lumley MA, Smith JA, Longo DJ. The relationship of alexithymia to pain severity and impairment among patients with chronic myofascial pain: comparisons with self-efficacy, catastrophizing, and depression. J Psychosom Res. 2002;53(3):823-830.

38. Bagby RM, Parker JD, Taylor GJ. The twenty-item Toronto Alexithymia Scale - I. Item selection and cross-validation of the factor structure. J Psychosom Res. 1994;38(1):23-32.

39. Japanese Institute of Health Psychology. Lazarus Type Stress Inventory. Tokyo: Jitsumu Kyoiku Shuppan; 1996.

40. Folkman S, Lazarus RS. Ways of Coping Questionnaire Manual. Palo Alto, CA: Consulting Psychologists Press; 1988.

Neuropsychiatric Disease and Treatment

\section{Publish your work in this journal}

Neuropsychiatric Disease and Treatment is an international, peerreviewed journal of clinical therapeutics and pharmacology focusing on concise rapid reporting of clinical or pre-clinical studies on a range of neuropsychiatric and neurological disorders. This journal is indexed on PubMed Central, the 'PsycINFO' database and CAS.
41. De Gucht V, Maes S. Explaining medically unexplained symptoms: toward a multidimensional, theory-based approach to somatization. J Psychosom Res. 2006;60(4):349-352.

42. Jensen MP, Turner JA, Romano JM. Changes in beliefs, catastrophizing, and coping are associated with improvement in multidisciplinary pain treatment. J Consult Clin Psychol. 2001;69(4):655-662.

43. Son SH, Jo H, Rim HD, et al. A comparative study on alexithymia in depressive, somatoform, anxiety, and psychotic disorders among Koreans. Psychiatry Investig. 2012;9(4):325-331.

44. De Gucht V, Heiser W. Alexithymia and somatization: quantitative review of the literature. J Psychosom Res. 2003;54(5):425-434.

45. Hartman TC, Borghuis MS, Lucassen PL, van de Laar FA, Speckens AE, van Weel C. Medically unexplained symptoms, somatization disorder and hypochondriasis: course and prognosis. A systematic review. J Psychosom Res. 2009;66(5):363-377.

46. Jones MP, Schettler A, Olden K, Crowell MD. Alexithymia and somatosensory amplification in functional dyspepsia. Psychosomatics. 2004;45(6):508-516.

47. Kano M, Fukudo S. The alexithymic brain: the neural pathways linking alexithymia to physical disorders. Biopsychosoc Med. 2013;7(1):1.

48. Nakao M, Barsky AJ, Kumano H, Kumoki T. Relationship Between Somatosensory Amplification and Alexithymia in Japanese Psychosomatic Clinic. Psychosomatics. 2002;43(1):55-60.

49. Waller E, Scheidt CE. Somatoform disorders as disorders of affect regulation: a study comparing the TAS-20 with non-self-report measures of alexithymia. J Psychosom Res. 2004;57(3):239-247.

50. Fukunishi I, Rahe RH. Alexithymia and coping with stress in healthy persons: alexithymia as a personality trait is associated with low social support and poor responses to stress. Psychol Rep. 1995;76(3 Pt 2): 1299-1304.

51. Grynberg D, Chang B, Corneille O, et al. Alexithymia and the processing of emotional facial expressions (EFEs): systematic review, unanswered questions and further perspectives. PLoS One. 2012;7(8):e42429.

52. Moriguchi Y, Komaki G. Neuroimaging studies of alexithymia: physical, affective, and social perspectives. BioPsychoSocial Medicine. 2013;7:8.

53. Pedrosa Gil F, Ridout N, Kessler H, et al. Facial emotion recognition and alexithymia in adults with somatoform disorders. Depress Anxiety. 2009;26(1):E26-E33.

54. De Greck M, Scheidt L, Bolter AF, et al. Altered brain activity during emotional empathy in somatoform disorder. Hum Brain Mapp. 2012;33(11):2666-2685.

55. Berthoz S, Pouga L, Wessa M. Alexithymia from the social neuroscience perspective. In: Decety, J, Cacciopo J, editors. The Oxford Handbook of Social Neuroscience. New York, NY: Oxford University Press; 2011: 906-934.

56. Rufer M, Albrecht R, Zaum J, et al. Impact of alexitymia on treatment outcome: a naturalistic study of short-term cognitive-behavioral group therapy for panic disorder. Psychopathology. 2010;43(3):170-179.

57. Kroenke K. Efficacy of treatment for somatoform disorders: a review of randomized controlled trials. Psychosom Med. 2007;69(9):881-888.

58. Looper KJ, Kirmayer LJ. Behavioral medicine approaches to somatoform disorders. J Consult Clin Psychol. 2002;70(3):810-827.

59. Sumathipala A. What is the evidence for the efficacy of treatments for somatoform disorders? A critical review of previous intervention studies. Psychosom Med. 2007;69(9):889-900.

The manuscript management system is completely online and includes a very quick and fair peer-review system, which is all easy to use. Visit http://www.dovepress.com/testimonials.php to read real quotes from published authors. 